\title{
Removal of Harmful Organic Compounds in Water Using Temperature-Sensitive Polymer Gel
}

\author{
HIDEKI YAMAMOTO ${ }^{1,2}$, NORIYUKI HEYAMOTO ${ }^{1}$ \\ AND JUNJI SHIBATA ${ }^{1,2}$ \\ ${ }^{1}$ Department of Chemical Engineering, Faculty of Engineering, \\ Kansai University, Suita 564-8680, Japan \\ ${ }^{2}$ High Technology Research Center (HRC), Kansai University, \\ Suita 564-8680, Japan
}

Keywords: Temperature-Sensitive Gel, Polyvinylalcohol, Volume Change, Adsorption, Removal,
1,2-Dichloroethane, Temperature Swing

The removal of harmful organic materials in water has been carried out using the adsorption and desorption characteristics of a temperature-sensitive polymer gel which is synthesized from polyvinylalcohol (PVA). Two types of polymerization degrees (1700 and 2500) of PVA were used in this experiment. The gel volume in water was induced at around $310 \mathrm{~K}$ for 1700 and $320 \mathrm{~K}$ for 2500 . At higher temperatures, the temperature sensitive polymer gel shrinks because of discharging water, whereas, in contrast, at lower temperatures, the gel swells as a result of absorbing water. The reversibility of the volume change of the synthesized polymer gel is confirmed by changing temperature.

The adsorption behavior of organic compounds onto PVA polymer gels in water was investigated at various temperatures. The amount of adsorption of organic compounds increases remarkably at temperatures higher than about $310 \mathrm{~K}$ for 1700 and $320 \mathrm{~K}$ for 2500 . The organic compound in water could be adsorbed and desorbed reversibly onto PVA polymer gel by the temperature swing. The mechanism of adsorption and desorption of organic compounds onto gel can be explained by the hydration and dehydration of the polymer gel. The driving force of the adsorption is thought to be the hydrophobic interaction between PVA polymer gel and organic compounds.

\section{Introduction}

The removal of harmful organic compounds such as dioxin, chloroform and 1,2-dichloroethane in ground water and drinking water are indispensable for the protection of the environment. In particular, the development of a new removal or disposal method for harmful organic materials in water is very important from a practical point of view.

Under the appropriate control of chemical and cross-link structures, certain polymer gels exhibit property or molecular shape changes in response to slight changes in the external environment such as temperature, solvent composition, magnetic field, $\mathrm{pH}$ and light (Xia et al., 1987; Seida and Nakano, 1994; Saulius et al., 2000). These gels are called environment-sensitive polymer gels, or intelligent materials, and their application in artificial muscles and drug delivery systems has been investigated. The environment-sensitive polymer gels reported to date are poly- $N$-isopropyl-

Received on September 17, 2002. Correspondence concerning this article should be addressed to H. Yamamoto (E-mail address: yhideki@kansai-u.ac.jp). acrilamide (NIPA) and poly-vinylmethylether (PVME) (Hirotsu et al., 1987; Seida and Nakano, 1992; Yamagiwa et al., 1993).

The present research group identified a polymer gel that is primarily composed of polyviniylalcohol (PVA). The gel is partially cross-linked and acts as a temperature-sensitive polymer gel that expands or contracts according to changes in temperature (Yamamoto and Shibata, 2001). The reversible phenomenon of volumetric contraction of up to $30-40 \%$ in response to a temperature rise from 280 to $310 \mathrm{~K}$ was confirmed in previous work (Yamamoto and Sibata, 2001). The expansion and contraction behaviors of this polymer gel have been explained in terms of the hydration and dehydration of the gel. The PVA polymer gel presented in this study is found to be environmentally-sensitive toward temperature. The polymer gel is a high-functional material that has a potential application as a carrier for organic substance removal and chemical substance transportation systems.

In this work, removal experiments of harmful organic materials in water were carried out using adsorption and desorption characteristics with temperature changes applied to the temperature-sensitive PVA polymer gel. 
Table 1 Chemical structure of PVA polymer gel

Poly vinyl alcohol(bridging) (PVA)

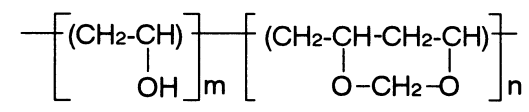

\section{Materials}

The polyvinylalcohol (PVA) was supplied by KRARY Co., Ltd. The degree of saponification was $99.8 \mathrm{~mol} \%$, and two types of polymerization degrees, 1700 and 2500, were used in this study.

1,2-Dechloroethane was chosen as the harmful organic compound for the adsorption removal experiments. The reagent grade 1,2-dichloroethane was supplied from Wako Pure Chemicals Co. The purity was $99.5 \%$, and it was used without further purification.

\section{Experimental}

\subsection{Synthesis of PVA polymer gel}

The polyvinylalcohol (PVA) was initially generated from vinyl acetate. The degree of saponification was $99.8 \mathrm{~mol} \%$, and the polymerization degree was 1700 or 2500 . Sodium alginate $(1 \mathrm{wt} \%)$ and sodium hydrogen carbonate $(0.3 \mathrm{wt} \%)$ solutions were added to the PVA ( $8 \mathrm{wt} \%$ ) for the preparation of a mixed solution. Using a roller pump with a silicone tube of $4 \mathrm{~mm}$ internal diameter and a nozzle with an internal diameter of $3 \mathrm{~mm}$, the solution was added to a stirred calcium chloride solution $\left(0.1 \mathrm{mg} / \mathrm{dm}^{3}\right)$ at $5 \mathrm{~cm}^{3} / \mathrm{min}$. Sodium alginate was solidified on the surface of each drop from the nozzle to make calcium alginate in the calcium chloride solution. The solids obtained were spherical. These spherical solids were soaked in an aqueous solution containing formaldehyde $\left(0.02 \mathrm{~kg} / \mathrm{m}^{3}\right)$, sulfuric acid $\left(0.2 \mathrm{~kg} / \mathrm{m}^{3}\right)$, and sodium sulfate $\left(0.1 \mathrm{~kg} / \mathrm{m}^{3}\right)$ for $60 \mathrm{~min}$ at $313 \mathrm{~K}$. Then, the solidified gel was fixed with acetal bonding and the degree of cross-linking was about $50 \%$. The chemical structure of the PVA polymer gel is listed in Table $\mathbf{1 .}$

\subsection{Measurement of volumetric change with tem-} perature swing

The spherical gels of about $5 \mathrm{~mm}$ diameter in water, were used in the experiments in the temperature range from 273 to $353 \mathrm{~K}$. The average diameter of the spherical gel was calculated from a digital image on a computer screen, and the volume was calculated (a) Polymerization degree : 1700

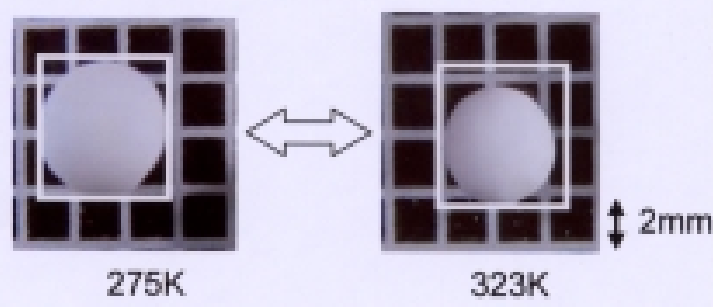

(b) Polymerization degree : 2500

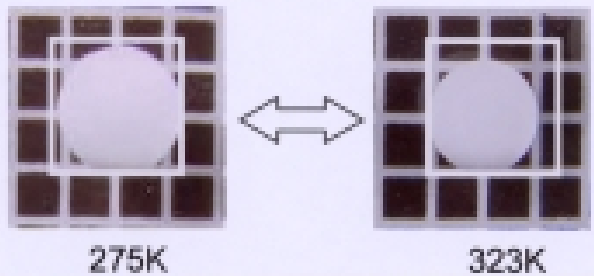

Fig. 1 Volume change of temperature-sensitive PVA polymer gel in water at $275 \mathrm{~K}$ and $323 \mathrm{~K}$

assuming the PVA polymer gel to be perfectly spherical. The reversibility of the volumetric change of the gel for temperature changes in water was investigated. The accuracy of volumetric measurement and reversibility of volumetric change with temperature swing were estimated $\pm 2 \%$.

\subsection{Measurement of adsorption of organic com- pound}

Adsorption experiments of a small amount of organic compound onto PVA polymer gel in water was carried out for temperatures ranging from 293 to $333 \mathrm{~K}$. The initial concentration of the organic compound in water was $200 \mathrm{mg} / \mathrm{dm}^{3}$. An aqueous solution of 100 $\mathrm{cm}^{3}$ containing organic compound and 50 gels of $5 \mathrm{~mm}$ diameter were introduced into a $300-\mathrm{cm}^{3}$ flask at room temperature. The flask was shaken using a shaker for $60 \mathrm{~min}$ in a constant temperature water bath. The adsorption experiments were carried out for temperatures ranging from 293 to $333 \mathrm{~K}$. The amount of adsorption onto the PVA polymer gel was determined from the difference between the initial and the final concentrations of the organic compound. The concentration of organic compound in the water was measured using gas chromatography with a capillary column. The effect of the vapor-liquid equilibrium of the organic compound at the temperature swing was corrected by a blank test at each temperature.

\section{Results and Discussion}

\subsection{Volumetric change of PVA polymer gel with temperature swing}

Figure 1 shows the volumetric change of the PVA polymer gel with temperature. The volumetric changes 


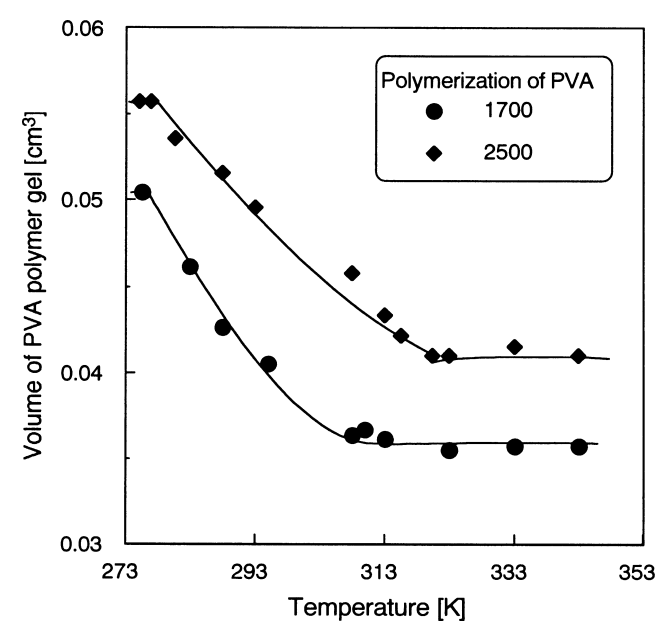

Fig. 2 Volumetric change of PVA polymer gel at various temperatures. Polymerization degrees of PVA are 1700 and 2500. Leaving time is $1 \mathrm{~h}$

of the PVA polymer gel of the two polymerization degrees (1700 and 2500) are shown in the figure. The spherical gel with $5 \mathrm{~mm}$ diameter in water at temperatures ranging from 273 to $280 \mathrm{~K}$ contracts with increasing temperature to about $4 \mathrm{~mm}$ diameter at $310 \mathrm{~K}$ or higher for PVA polymer gel (1700). In the case of polymer gel (2500), the contraction takes place at $320 \mathrm{~K}$ or higher. It is found that the transition temperature of the shape shifts changes with the degree of polymerization. The average diameter was obtained from a digital image on a computer screen, and the volume was calculated assuming the PVA polymer gel to be perfectly spherical.

Figure 2 shows the change in gel volume of the polymerization degree (1700) in water as a function of temperature. The gel volume becomes smaller with increasing temperature. At temperatures of $313 \mathrm{~K}$ or higher, volumetric contraction can not be confirmed. In the case of the polymerization degree (2500), similar results are obtained at temperatures higher than 320 $\mathrm{K}$, as shown in Fig. 2.

The above results demonstrate that two types of PVA polymer gel are temperature sensitive, contracting by about 30 to $40 \%$ in volume in water, depending on temperature. The reversibility of the volumetric change of the gel in water is confirmed by five experimental trials with an accuracy of about $\pm 3 \%$ (Yamamoto and Sibata, 2001). The reversibility of the volumetric expansion and contraction of the PVA polymer gel as the changes in temperature was investigated by observing these behaviors.

\subsection{Adsorption behavior of organic compound onto \\ PVA gel in water}

In order to examine the change in the surface property of the polymer gel with changes in temperature, adsorption experiments of an organic compound in water were carried out at temperatures of 298 and

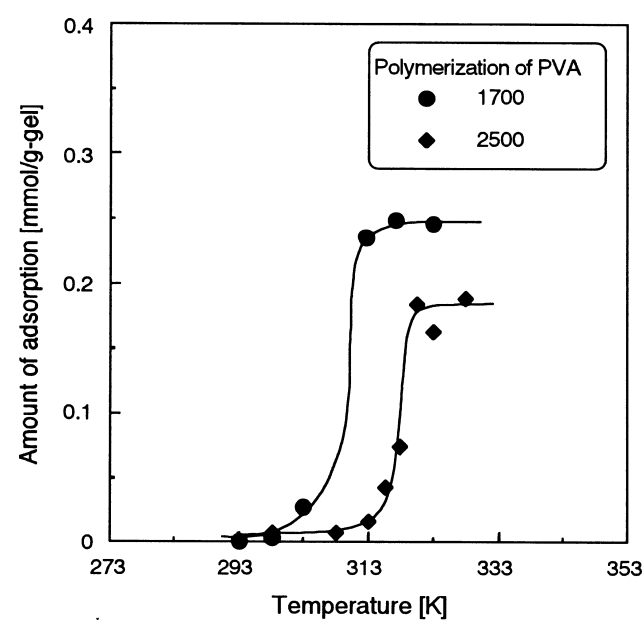

Fig. 3 Adsorption amount of 1,2-dichloroethane onto PVA polymer gel at various temperatures. Polymer degrees of PVA are 1700 and 2500 . Gel number is 50 . Initial conc. is $200 \mathrm{mg} / \mathrm{dm}^{3}$. Solution is $100 \mathrm{~cm}^{3}$. Shaking time is $1 \mathrm{~h}$

$323 \mathrm{~K}$. 1,2-Dichloroethane was chosen as the organic material for the adsorption removal experiments. Figure 3 shows the amount of adsorption of 1,2dichloroethane onto the PVA polymer gel (1700) at different temperatures. The PVA polymer gel adsorbs 1,2-dichloroethane in a contracted state which corresponds to a temperature of $310 \mathrm{~K}$ or higher, compared with that in an expanded state which corresponds to a temperature of $298 \mathrm{~K}$ or lower. The amount of adsorption of 1,2-dichloroethane in aqueous solution at $323 \mathrm{~K}$ or higher is $0.25 \mathrm{mmol} / \mathrm{g}$-gel, which is a higher value than that at $298 \mathrm{~K}(0.01 \mathrm{mmol} / \mathrm{g}$-gel $)$. This indicates that a contracted state eliminates water easily from the surface of the gel to make the surface hydrophobic. The relationship between the amount of adsorption of 1,2-dichloroethane onto PVA polymer gel (2500) and temperature is shown in Fig. 3. The amount of adsorption of 1,2-dichiloroetane in aqueous solution at $323 \mathrm{~K}$ is $0.20 \mathrm{mmol} / \mathrm{g}$-gel, which is a much higher value than that at $298 \mathrm{~K}(0.02 \mathrm{mmol} / \mathrm{g}$-gel $)$. This also indicates that the expanded state holds water easily at the surface of the gel due to hydrogen bonding. The difference in the amount of adsorption between the two temperatures can be applied to the new removal system of harmful organic compounds in water using temperature changes. Figure 4 shows the adsorption isotherm of 1,2-dichiloroetane in water onto two types of PVA polymer gels at $323 \mathrm{~K}$. The saturated value of the adsorption equilibrium for 1,2-dichiloroetane onto the PVA polymer gel (1700) at $323 \mathrm{~K}$ is higher than that of 2500.

3.3 Adsorption mechanism of organic compounds onto PVA polymer gel

In order to discuss the surface condition of PVA polymer gel in organic solvents, the thickness of a water 


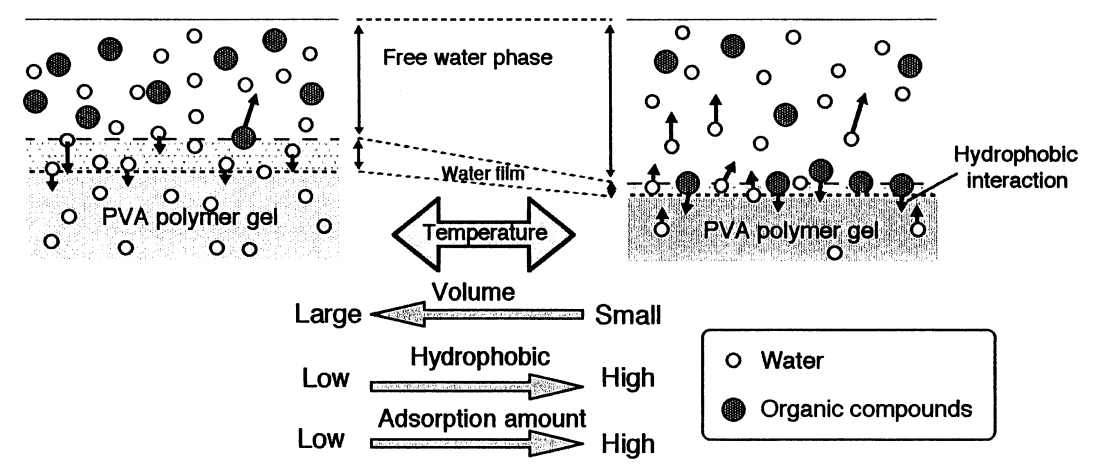

Fig. 5 Mechanism of the adsorption-desorption process of organic compounds on PVA polymer gel

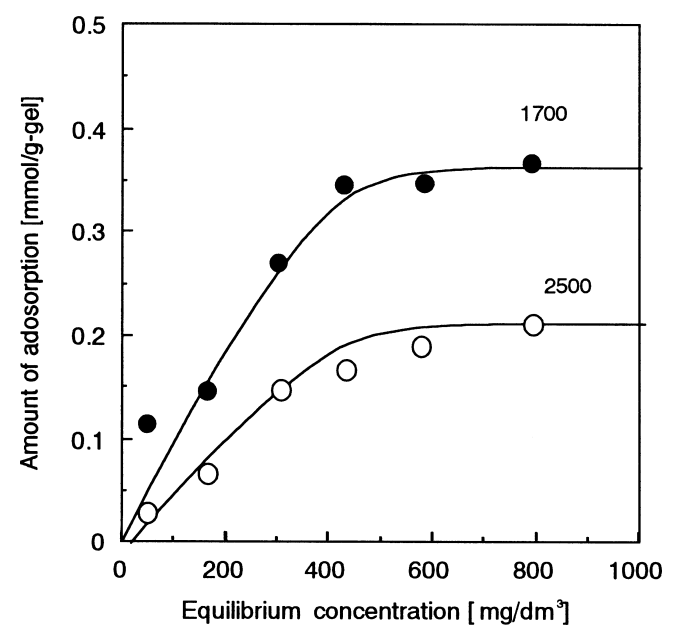

Fig. 4 Adsorption isotherm of 1,2-dichloroethane onto PVA polymer gel in water at $323 \mathrm{~K}$. Polymerization of PVA are 1700 and 2500. Gel number is 50. Solution is $100 \mathrm{~cm}^{3}$. Shaking time is $1 \mathrm{~h}$

film at the gel surface in toluene was examined using a digital camera. The PVA polymer gel containing water was immersed in toluene for $24 \mathrm{~h}$ at 298, 310 and 323 $\mathrm{K}$. The gel volume becomes small with increasing temperature of toluene. The result of volumetric contraction is quite similar to that in water. The thickness of the water film of the PVA polymer gel in toluene becomes thinner with increasing temperature. At the higher temperature of $323 \mathrm{~K}$, the water film on the PVA disappeared on the computer screen of the digital camera. It is thought that the result mainly depends on the balance of the hydrophobic and hydrophilic properties of the PVA polymer gel surface with temperature changes, that is, the hydrophobility of the gel surface at $323 \mathrm{~K}$ is higher than that at $298 \mathrm{~K}$. As a result, the amount of adsorption of 1,2-dichiloroethane onto the gel at $323 \mathrm{~K}$ becomes higher compared with that at $298 \mathrm{~K}$.

Figure 5 shows the mechanism of the adsorption and desorption behavior of organic compounds onto PVA polymer gel due to changes in temperature. The expansion and contraction behaviors are mainly caused by hydration and dehydration. The PVA polymer gel in a constructed state at temperatures higher than 310 or $320 \mathrm{~K}$ has an adsorption ability for organic compounds in water. It shows that the balance of the hydrophobic and hydrophilic properties of the surface of the PVA polymer gel can be controlled by the temperature of the solvent. The driving force of this adsorption is the hydrophobic interaction between the PVA polymer gel and organic compounds in the contracted state.

\subsection{Removal experiment of 1,2-dichiloroethane in water}

Figure 6 shows the adsorption removal experiment of 1,2-dichiloroethane in water using an air lifting type vessel at a small scale. The volume of the air lifting vessel was about $20 \times 10^{-3} \mathrm{~m}^{3}$ and it was covered by an insulating material. 3000 pieces of spherical polymer gels of about $5 \mathrm{~mm}$ in diameter were introduced into this vessel. Air is supplied by an air bomb into the vessel from the nozzle fixed at the bottom of the vessel in order to mix the polymer gels and aqueous solution uniformly. The flow rate and initial concentration of the solution of 1,2-dichiloroethane were $0.5 \times 10^{-3} \mathrm{~m}^{3} / \mathrm{min}$ and $8.0 \mathrm{mg} / \mathrm{dm}^{3}$, respectively. The temperature of the aqueous solution was controlled at about $315 \mathrm{~K}( \pm 2 \mathrm{~K})$ by a panel heater. The outlet concentration of 1,2-dichiloroethane was measured by gas chromatography. Figure 7 shows the relationship between time and the outlet concentration of 1,2dichiloroetane in aqueous solution. The theoretical breakthrough time of 1,2-dichiloroetane can be calculated from the experimental conditions (flow rate and concentration) and the saturated value of the adsorption $(0.26 \mathrm{mmol} / \mathrm{g}$-gel $)$ obtained in Fig. 4 . In the case of this experimental condition, theoretical breakthrough time was obtained as about $90 \mathrm{~min}$.

It is confirmed that the breakthrough time for the adsorption experiments is about $55 \mathrm{~min}$, which is shorter than is suggested in theory. This result demonstrates that the PVA polymer gel can be utilized as a removal system for harmful organic materials in water 

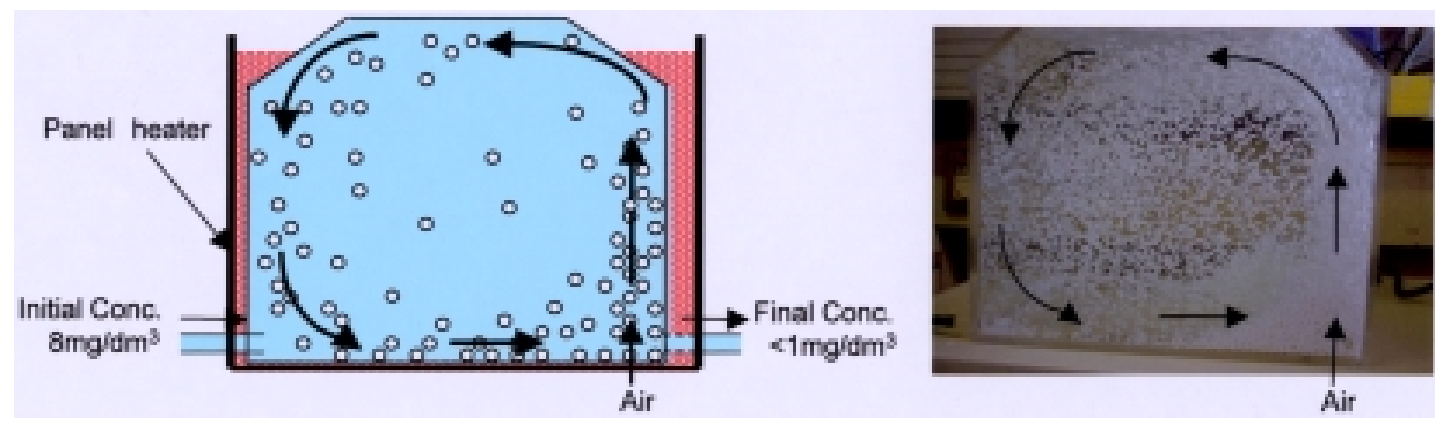

Fig. 6 Adsorption removal test of 1,2-dichloroethane in water using an air lifting type continuous apparatus. Polymerization degree of PVA is 1700 . Gel number is 3000 . Volume is $20 \times 10^{-3} \mathrm{~m}^{3}$. Temperature is $315 \mathrm{~K}( \pm 2 \mathrm{~K})$. Flow rate is $0.5 \times 10^{-3} \mathrm{~m}^{3} / \mathrm{min}$. Residence time is $40 \mathrm{~min}$

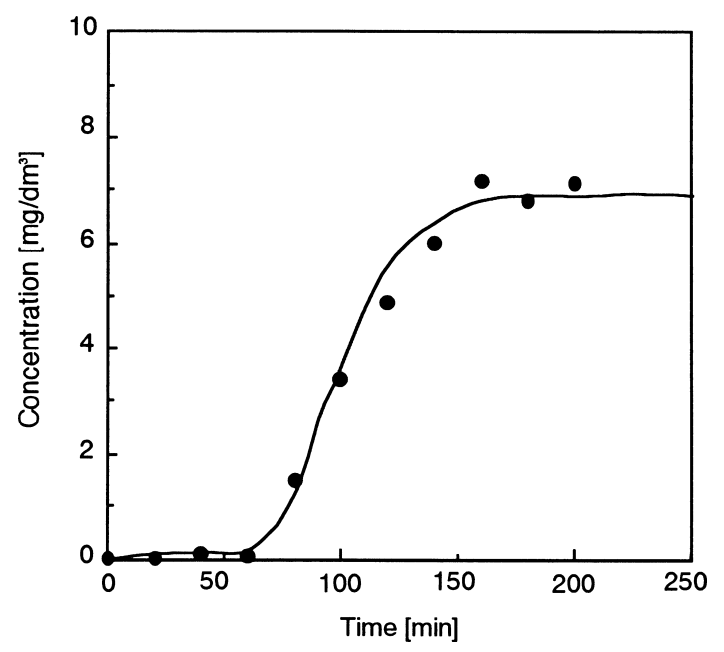

Fig. 7 Adsorption removal of 1,2-dichloroethane using PVA gel

such as ground water or drinking water.

\section{Conclusions}

It is found that the polymer gel synthesized from PVA is a temperature-sensitive polymer gel. The volume of the gel in water changed at around $310 \mathrm{~K}$ for the polymerization degree (1700) and at $320 \mathrm{~K}$ for the polymerization degree (2500). At higher temperatures, the PVA polymer gel shrank because of discharging water, whereas, in contrast, at lower temperatures the gel swelled because of the absorption of water due to hydrogen bonding. The amount of adsorption of organic compounds onto the PVA gel increases remarkably at temperatures higher than these. The PVA polymer gel could be effective for the adsorption removal of an extremely small amount of harmful organic com- pounds in water, and they are repeatedly usable as an adsorbent. The mechanism of adsorption of organic compounds onto the PVA polymer gel can be explained by the hydration and dehydration of the gel. This polymer gel is a high-functional material that has potential applications as a carrier for organic substance adsorption and chemical substance transportation systems. From the results obtained in this work, the PVA polymer gel is expected to have applications in drug delivery systems and as a removal system for toxic organic compounds in water using the reversible volume change.

\section{Acknowledgment}

This work was partly supported by a grant from the High Technology Research Center (HRC) at Kansai University. We appreciate the material support and valuable cooperation of KRAREY Co., Ltd.

\section{Literature Cited}

Hirotsu, S., Y. Hirokawa and T. Tanaka; "Volume-Phase Transitions of Ionized N-Isopropylacrylamide Gels," J. Chem. Phys., 15, 1392-1395 (1987)

Saulius, J., N. Mukai, R. Wakaki, A. Yamaguchi, S. Matsuo and H. Misawa; "Reversibility Phase Transition in Polymer Gels Induced by Radiation Forces," Nature, 408, 178-181 (2000)

Seida, Y. and Y. Nakano; "Surface Property of Temperature Sensitive $\mathrm{N}$-isopropylacrylamide Copolymer Gel," Kagaku Kogaku Ronbunshu, 18, 346-352 (1992)

Seida, Y. and Y. Nakano; "The Physical and Chemical Structure of Temperature Sensitive Polymer Gel and Its Surface Property," Kagaku Kogaku Ronbunshu, 20, 213-218 (1994)

Xia, H., H. Unno, T. Akehata and O. Hirasa; "Analysis of Kinetic Behavior of Temperature Sensitive Water Absorbing Hydrogel," J. Chem. Eng. Janan, 20, 123-128 (1987)

Yamagiwa, K., T. Sasaki, A. Ohkawa and O. Hirasa; "Adsorption of Hydrophobic Nonionic Surfactant on Poly(vinylmethylether) Gel," J. Chem. Eng. Janan, 26, 747-748 (1993)

Yamamoto, H. and J. Shibata; "Absorption of 1,2-Dichloroethane in Water Using Temperature Sensitive Polymeric Hydrogel and Its Mechanism,” Kagaku Kogaku Ronbunsyu, 27, 786-791 (2001) 